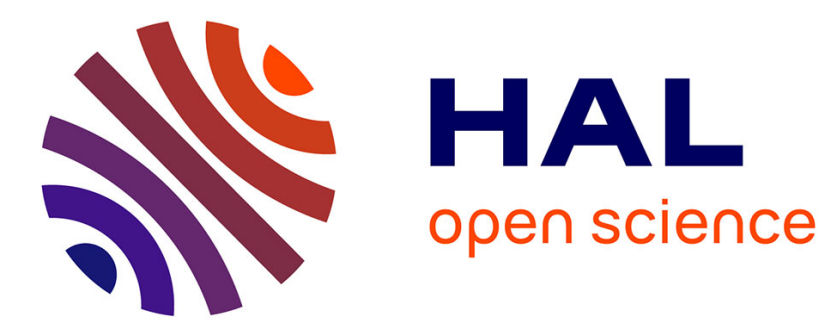

\title{
Comedy in the Ludonarrative of Video Games
}

Oskari Kallio, Masood Masoodian

\section{To cite this version:}

Oskari Kallio, Masood Masoodian. Comedy in the Ludonarrative of Video Games. 17th International Conference on Entertainment Computing (ICEC), Sep 2018, Poznan, Poland. pp.115-126, 10.1007/978-3-319-99426-0_10 . hal-02128618

\section{HAL Id: hal-02128618 \\ https://hal.inria.fr/hal-02128618}

Submitted on 14 May 2019

HAL is a multi-disciplinary open access archive for the deposit and dissemination of scientific research documents, whether they are published or not. The documents may come from teaching and research institutions in France or abroad, or from public or private research centers
L'archive ouverte pluridisciplinaire HAL, est destinée au dépôt et à la diffusion de documents scientifiques de niveau recherche, publiés ou non, émanant des établissements d'enseignement et de recherche français ou étrangers, des laboratoires publics ou privés. 


\title{
Comedy in the Ludonarrative of Video Games
}

\author{
Oskari Kallio and Masood Masoodian \\ School of Arts, Design and Architecture \\ Aalto University \\ Finland \\ \{oskari.kallio, masood.masoodian\}@aalto.fi
}

\begin{abstract}
Although humor is a prevalent component of numerous video games, thus far it has not been recognized as an established genre of its own. Comedy - the deliberate act to harness and perform humorrepresents one, but an important segment of the emotional range that video games should aspire to cover. The challenge, however, lies in attempting to analyse various elements contributing to comedy, particularly with the inclusion of interactively as a fundamental element of video games. In this paper, we propose using the concept of ludonarrative as the basis for analysing comedy in video games. We approach ludonarrative comedy through examples that illustrate trends which can be discerned from games that introduce humor through their narrative and ludic (gameplay-related) elements.
\end{abstract}

Keywords: Computer games · Video games · Comedy $\cdot$ Humor $\cdot$ Narrative $\cdot$ Ludonarrative $\cdot$ Ludology $\cdot$ Narratology.

\section{Introduction}

Comedy is the performance of humor, which is why comedy cannot be analyzed without the understanding of what humor is. Hookam and Meany [16] define humor as the "ability to perceive or express the intentional or unintentional comic elements of life", and comedy as the "intentionally structured cultural product that employs particular forms and conventions to create the affect of amusement in an audience." Martin [23] describes humor as "a ubiquitous human activity that occurs in all types of social interaction. It infuses meaning to the meaningless and takes it away from matters that are perhaps too meaningful."

Although various humor theories [29] attempt to describe what is at the core of a humorous experience, there is no accepted unified theory of funny, nor a precise formula for humor creation-only intuition.

If comedy is rather difficult to define, it is even more so when the element of interactivity of video games ${ }^{1}$ is made part of the equation. It is not surprising then that, while words "comedy" and "humor" are commonly used to describe specific genres of films and books, they are hardly ever used to describe video games. Furthermore, although "humor" is a prevalent element in many games,

\footnotetext{
${ }^{1}$ In this paper, we use "video games" and "computer games" interchangeably.
} 
only a few of them seem to warrant the "comedy" label. However, the few comic games that do exist, are proof of the comedic capability that the medium holds. In many ways the medium of video games is perfect for comedy - with the means of play, games can actually involve their audience in the comedy-making. Hookam and Meany [16] note that for video games comedy to be recognized as a genre, there must first be a consensus on the elements that contribute to such comedy.

In this paper, we analyze video games comedy using the concept of ludonarrative. The term "ludonarrative", coined by game designer Clint Hocking [15], comes from the Latin word ludus - roughly translating to "game" - and narrative - referring to a meaningful recount of connected events. In short, ludonarrative refers to the junction of gameplay and narrative elements in video games. Here, we define the qualities that make ludonarrative comedy distinct from comedy in other media, identify the challenges involved in its execution, and discuss three dimensions for the design of ludonarrative comedy in video games: their visual style, their sources of comedy, and the elements of conflict in them.

\section{Ludonarrative comedy}

Major literature reviews of humor and comedy in video games are rather scarce. Dormannn and Biddle [8] provide the first of such reviews, focusing primarily on the gameplay elements. Dormann [7] extends this work, while still keeping the focus on humor in gameplay. The most comprehensive review of humor in video games to date, however, is that of Grönroos [14], which identifies the role of player input in comedic aspects of video games, and relates this to game characters, game worlds, and game mechanics, as means of offering emergent humor. She also reviews the role of scripted (i.e. narrative) humor in video games.

These reviews show that video games provide a fitting, but an under-utilized, medium for comedy. However, Grönroos [14] suggests that this apparent lack of humor in video games may in fact be a question of recognition, with interactive humor taking new unfamiliar forms: "games use humor in ways that are unfamiliar from other media, and often humor elicits amusement instead of laughter."

Ludonarratives provide many opportunities for comedy. Games are enthralling, player-influenced and effort-requiring rule-based systems with variable and quantifiable outcomes that, while have values assigned to them, also have negotiable consequences [18]. Frasca [9] emphasizes that the "player agency" is what distinguishes interactive narratives from traditional narratives: "Observers are passive, the player is active. If the player does not act, there will be no game, and therefore no session at all." He also stresses that "play" and the "narrative" are not one, but play can lead to the creation of a narrative.

Ludonarrative comedy also generates its own unique design problems. For instance, comic timing - the fundamental and unforgiving factor in any kind of comedy - can be easily impaired by the player.

Therefore, designers of comedy games need to have an insight about the strengths and weaknesses of this particular medium. In comparing the neglected video games comedy to the established horror video games genre, Quinn [26] 
argues that the barriers to successful video games comedy are not mechanical in nature. She also points out that horror and comedy share many of the same qualities: they aspire to take their audience by surprise; with both there is usually a set-up and a pay-off; and the design problems are similar (e.g. the efforts to keep the material fresh). Quinn suggests that only by considering comedy as a mechanical foundation for gameplay, as well as having a firm understanding of what drives humor, the potential of video games comedy can be realized.

However, most developers still seem to avoid designing their games primarily around humor, and often use it like a seasoning to add flavor to the end result, with little relevance to the overall design. Pratchett (quoted in [21]) stresses that this sort of approach does not lead to true comedy: "Good humor needs to be built in. It should be the chocolate chips in the gooey cookie of gaming, rather than chocolate sprinkles on top."

Full commitment to comedy is seen as a risk because bad comedy has no value. A funny joke is a source of joy, but a bad one can be downright detrimental. Bell, having studied responses to failed humor [3], proposes that the reason a bad joke makes the listeners angry is because it is often taken as an insult to the audience's sense of humor: "When a joke is actually funny, listeners don't mind the disruption because there is a payoff: humor. Without the humor, listeners may become annoyed at the lame crack."

Furthermore, it is also difficult for non-integral comedy to make it all the way to the final product, simply because of the way most games are developed. A substantial part of the game development process involves the trial-and-error based playtesting. Constant playtesting equals repetition, which is known to sour even the funniest of jokes. Humor is a transient delight. Repetition - when used correctly - is a comic enhancer, but without variation it can make the humor disappear. Root (quoted in [11]) highlights that "Surprise is one of the keys to comedy, and it's difficult to pull off in a game with repeat plays." Schafer [25] also emphasizes that game designers must be hypersensitive about repetition: "There is an old expression, don't put humor on the inner loop. Nothing is funny that many times in a row. OK, I just made that up but it's true. Characters need to change up what they say, not just to keep the humor fresh, but to make the character seem more real." Quinn [26] compares playtesting for comedic games to stand-up comedians who are constantly refining their material with fresh audiences: "Test early, test often and with new people." Therefore, the role of playtesting should not be about discarding comedy, but making it funnier.

Abbott [1] argues that comedy is "cerebral, technical, and deeply human", and notes that, of those three factors, comedic video games often stumble in the "deeply human" department. Abbot supports his claim with the gradual disappearance of comedic games towards the beginning of the new millennium, when video game visuals started transitioning from primitive to more photorealistic. He links this observation to the "uncanny valley" theorem, which maintains that the closer a human replica gets to a real human, the more unnatural it appears to the (human) observer: "The uncanny valley is nobody's friend, but it's an especially harsh environment for comedy." When games fail the comedic Turing 
test, it is likely that something about their humor is too foreign or unrecognizable to be considered funny. While the player can be used to fill the "deeply human" void in ludonarrative comedy, there are many fundamental, and largely unaddressed, problems in using the player as a component in a comic gameplay. At the very least, in such cases when players' efforts result in failure, they are more likely to end up being disappointed rather than amused. Failure can be turned into comedy, as long as the players themselves are not the laughing stock.

So one of the key questions in ludonarrative comedy is how to make players to commit to comedy. Totilo [28] calls attention to the dualistic role a player is designated in a video game. Players are not only members of the audience, but are also playing the part of the lead actor. When the objectives of a game are clear and the gameplay revolves around active verbs, players can be expected to play their part, but when the concept of "nuance" is introduced, requirements for the players' performance increase. "It's easy for a game designer to make someone feel like Bruce Willis or Sly Stallone by putting a virtual gun in their hand. But how do you go about making someone feel like Charlie Chaplin or Bernie Mac", Totilo contemplates [28].

\section{Visuality of ludonarrative comedy}

Humor has an aesthetic dimension that has long been recognized. Morreall [24] claims that aesthetic experience is the basis of all humor, while Gordon [12] describes humor as being "aesthetic to the extent that it arouses the viewers' imagination, provides them with insights about human existence, and provokes them to think more critically and creatively." Because video games are a visual medium, aesthetics have an important role in their delivery of humor. They can either be used to tell visual jokes, or prepare the audience for comedic experiences. Visual cues, such as the overall visual style, character design, and animations can condition the audience to get into a humorous mood.

For instance, Katamari Damacy ${ }^{2}$, utilizes all of the above mentioned enhancers to produce a playable visual gag. The game uses its psychedelic aesthetics to highlight the eccentricity of its ludonarrative. A small glimpse of the visuals is enough to reveal that the game is not to be taken too seriously. The delightful animations and overly simple geometry of the in-game objects contribute to the carnivalistic style. A visual gag is something that cannot be translated to any other form, and Katamari Damacy is a prime example of that.

Video games also share many similarities with animated films, as with both, the directors are by and large responsible for the finished product. The fantastical canvas of games and cartoons makes it possible for the director to portray any imaginable idea. Tex Avery, a longtime animation director for Warner Bros. ${ }^{3}$ in the early 20th century, had an enormous influence on animated comedy. He is responsible for both inventing and institutionalizing a great number of visual gags, that have since become standard visual language in narrative animation.

\footnotetext{
${ }^{2}$ Namco (2004), Playstation 2.

${ }^{3}$ https://www.warnerbros.com
} 
Eyes popping out of the characters' heads when shocked, their jaws dropping to the floor in astonishment, and gravity playing tricks on them, are all part of Avery's trademark comedy. Avery knew that the audience is aware of the fact that everything that happens on the screen has been manufactured, and used the fictitious mould of animation for yet more comedy. For instance, some of his cartoons used black rotoscoped human silhouettes on top of the actual animation, that were meant to trick the movie audience into believing that somebody had stood up in the theater to chat with the characters of his films. His other films featured a drawn fluttering hair on screen, as if it was stuck inside the projector. Eventually a character would notice the hair and pull it out. The visual humor of Avery comes from the realization that the animation directors are not bound by the laws of the nature, and have the freedom to do whatever they wish with the format. In a like manner there is still much to be extracted from the freedom that comes with the unique properties of video games.

The Outcast $^{4}$ video game features comparable comic antics. The game jests at deficiencies of the digital medium with a pretend blooper reel with simulated bugs and glitches. The reel shows reactions of the in-game cast as the game soundtrack is playing too loud during conversations, characters colliding into each other during cutscenes, and the AI malfunctioning in amusing ways.

Tex Avery's heir at Warner Bros., Chuck Jones, distanced himself from the anarchy of the Avery era and emphasized creative discipline in cartoons [10]. Since the possibilities with animations were boundless, Jones established clearly defined systems and rules for his animations [2]. He found humor in strict conditions and animation systems that benefited the internal consistency of the cartoons. Jones concentrated on the smallest possible gestures and expressions in order to invoke mirth. "If you can't tell what is happening by the way the character moves, you're not really animating," he is quoted saying [34]. For video games, Jones' structural approach is easier to adapt than the boundlessness of Avery's method, because games themselves are closed formal systems.

Super Mario Odyssey ${ }^{5}$ provides a good example of animations that instantly tell the player what is happening. Mario is able to "capture" various enemies in order to control them. With each creature behaving and controlling in a comically distinct manner, the player gets instant feedback of their abilities. Much of what is humorous about the game is in the visual design, things appearing comical rather than being actual, and explicit visual gags.

In video games idle animations are also a popular means to communicate a character's personality and mood to the player. They usually happen when the player does not touch the controls of a game for a fixed amount of time. Idle animations in most cases are simple, such as the character glancing around the scenery or scratching its rear-end. They can, however, be used for simple visual gags, like in Rayman 2: The Great Escape ${ }^{6}$, where the joint-less protagonist takes its blob of a torso and uses it to practice basketball dribbles. In other cases, idle

\footnotetext{
${ }^{4}$ Infogrames (1999), Windows.

${ }^{5}$ Nintendo (2017), Nintendo Switch.

${ }^{6}$ Ubisoft (2000), Windows.
} 
animations have been used for character and world building purposes. One of the earliest examples is in Leisure Suit Larry in the Land of the Lounge Lizards ${ }^{7}$. The game begins on a nightly city street where Larry is waiting for the player interaction. Upon the player not touching the controls, a dog slowly walks into the scene, mistakes the stationary Larry for a lamppost, and urinates on him.

Comedy can also be generated purposefully through bad visual design. Terry Gilliam's animation transitions in Monty Python's Flying Circus ${ }^{8}$ remain a good example of such deliberately shoddy visual style. Similarly, the animation series South Park ${ }^{9}$ has became famous for having a clumsy approach to cut-out animation. Weinstock [33] argues that a big part of the initial success of South Park was due to "the tension established between its relatively sophisticated dialogue and involved narratives and its extremely limited animation." These show that, when cleverly executed, sub-par visuals can elevate the humor of a production.

Many low-budget games, having realized this, utilize intentionally bad animations and character designs to amuse the player. For instance, Surgeon Simulator $^{10}$ uses its coarse visual presentation to promote its funny gameplay premise, and to differentiate itself from the more serious simulator games. The game is set in an operation room, but the visual design underscores the farcicality of the player being the surgeon, rather than the vulgarity of the surgical procedure. Similarly, Enviro-Bear $2000^{11}$ elevates the comicality of its premise with purposefully cheap-looking visuals, and clunky controls. The game is about a bear driving a stolen a car on a mission to absorb as much nutrients as it can before winter starts and its hibernation begins.

\section{Sources of ludonarrative comedy}

The choice of who conducts the comedy in a video game largely defines the type of its ludonarrative comedy. Salen and Zimmerman [27] divide video game narratives into two types, embedded and emergent narratives. Embedded narrative is all the information the game wants to transmit to the player, whereas emergent narrative arises from the player interacting with the rules and the mechanics of the game. The two narrative structures overlap and are not always easily distinguishable as two different narrative experiences. Players not only experience an interactive story crafted for them, but also create their own personal narratives by engaging with the gameplay. Game designers have direct control over embedded narratives, but only indirect control over emergent narratives. Designers of course set the parameters of the game worlds and the functioning gameplay systems, but can never predict the exact actions the player will take.

Cook [5] postulates that game designers approach video game comedy design in similarly distinct ways. The first approach, humor-through-storytelling,

\footnotetext{
7 Sierra On-Line (1987), MS-DOS.

8 Monty Python's Flying Circus (1969-1973), BBC1 (1969-1973) and BBC2 (1974).

9 South Park (1997), Comedy Central.

10 Bossa Studios (2013), Windows.

11 Captain Games (2009), Windows.
} 
is a traditional one in which comedy is executed through conventional means of storytelling, including humorous writing, comic scenarios, and visual jokes. According to Cook, this style of comedy is emulated from other forms of entertainment, and therefore it is easily identifiable. The second approach, humor-throughmechanics, is unique to the interactive entertainment. This method involves the player as part of the "comedy-making" process by establishing gameplay mechanics or activities designed to cause comical conflicts (this will be discussed in the next section). Cook maintains that because gameplay mechanics are capable of generating nearly endless number of unique comedic situations, such emergent comedy can result in "evergreen humor." The two approaches emphasize different aspects of the comedic premise: humor-through-game-mechanics empowers the player as the comedian, whereas humor-through-storytelling exposes players to specific pre-defined humorous ideas. Although emergent comedy is unique to the interactive medium, the more finely-tuned comic plot-lines and concepts demand auteurism that only humor-through-storytelling can provide. To a large extent, comedy is the curation of ideas. It is about setting a framework and broadcasting a humorous point of view to the audience. However, when the responsibility to produce humor is placed on the player, comedy becomes coincidental instead of being methodical.

The third type of ludonarrative comedy, unintentional comedy, is one without a clear agency. This type of humor is found in the corruption of the game itself, in the form of bugs and glitches. They represent what Knox [19] regards as the essence in all humor, "playful chaos in a serious world." Glitches can be infuriating when they hinder or halt the player's progress, but their incongruousness can also cause unexpected mirth. Because unintentional comedy is a surprise to both the player and the game designer alike, it is one of the more clear examples of incongruous humor in video games. Incongruity theory [29] considers laughter as an effect that arises from the friction of two or more contrasting concepts. The bisociation, as Koestler [20] calls it, is a result of a shock effect that occurs when the two incompatible matrices conflict with the mind's expected and create a comic effect.

However, the incompetency of a game (or its designer) to perform tasksmalfunctioning physics engine or outlandishly twitching animations - can turn a serious game into an accidental comedy. Švelch [32] suggests that games that strive to represent real life but end up failing may become a subject of ridicule. Accidental comedy comes at the cost of taking the player away from the intended experience, which is why games seldom wish to be the subject of ironic laughter.

\section{Conflicts in ludonarrative comedy}

Vorhaus [31] asserts that comedy lives in the gap between the comic reality and the real reality. He contends that the gap, or a comic premise, as it is referred to, is a deliberately chosen point of view that is meant to reveal something humorous in a situation. Vorhaus outlines three recurring types of comical conflicts that lead to the comic premise. The first of the conflicts, the inner conflict, is about 
a character at war with itself. The second type of conflict is an interpersonal dispute between two or more characters, which Vorhaus calls the local conflict. The third type, the global conflict, is a conflict between a character and the world it is part of. The local and global conflicts can be identified in most comedic games. The inner conflict, being the most introspective of the three, is probably the rarest one to encounter.

\subsection{Inner conflict}

Vorhaus [31] outlines that the inner conflict is about exploration of the character and its emotions, making it a rich source for comedy and drama alike. Because the inner conflict is about the character being at war with itself as opposed to something external, the surrounding world does not often understand its behavior. To an external observer the actions of the character may seem absurd, as the comedy stems from its unusual and seemingly trivial aspirations. This often translates into comedy with low stakes, in which characters care too much about seemingly insignificant matters.

Incorporating the inner conflict as part of gameplay can make the player an active part of the character's psychological struggle. Dille and Platten [6] posit that through gameplay, a video game can show proportionality to the players and provide them with metrics by which they can measure their progress. By focusing on aspects of gameplay that are usually taken for granted, a game can make the players care about its low stakes. If turning everyday objects and scenarios into play is, as Bogost [4] argues, an inarguable strength of the medium, mundane circumstances can make a game as interesting as anything.

Octodad: Dadliest Catch ${ }^{12}$ exemplifies how contrasting the players' intent with their actual performance can reveal something about the inner conflict of the playable character. The central character of the game, Octodad, is an undercover dad in a regular human family doing his utmost to conceal his true identity, which is that he is in fact an octopus.

The browser-based game $Q W O P^{13}$ also subverts player's expectations, but through the way movements function in the game. The player is in control of an Olympic sprinter, who needs to reach the finish line in record time. The game uses four keyboard buttons, $\mathrm{Q}, \mathrm{W}, \mathrm{O}$, and $\mathrm{P}$, to control the calves and thighs of the sprinter (not its direction). Running does not require the use of directional controls, as the only thing that matters is propulsion-creating muscular tension in the correct parts of the leg. This makes QWOP almost impossible to control.

\subsection{Local conflict}

Vorhaus [31] describes the local (interpersonal) conflict as being a battle between two individuals. Usually one of the characters is comical, and another character contrasts it by being the more serious of the two. The characters involved might

\footnotetext{
12 Young Horses (2014), Windows.

13 Bennett Foddy (2008), Browser game.
} 
compete for a shared desire, or simply cross paths and collide while pursuing their own separate goals.

Untitled Goose Game ${ }^{14}$ finds comicality in the colliding interests of two characters. The player controls a wayward goose whose only goal is to torment an unsuspecting groundskeeper trying to do his job. The setup reinforces the stereotype that geese are inexplicably mean animals. The player is assigned to do mischievous tasks: steal the groundskeeper's keys, throw his rake in the lake, and steal food and other accessories to organize a picnic. Greyson [13] describes the game as being more about creating setups than causing straightforward mischief. The goose's animations are amusingly true to nature, for example it realistically huffs and spreads its wings as a sign of aggression when the groundskeeper gets too close to it.

The interpersonal conflict is well-suited for communal comedy, where two or more people are assigned roles with unambiguous objectives. Simply situating players in the same space creates a conflict between them. Such is the case with Who's Your Daddy ${ }^{15}$, an asymmetrical multiplayer game about the stress of babysitting. One person plays a parent in a race against the clock to babyproof a household, while the other player controls an infant in an attempt to drain their health to zero in any imaginable way. The goal of the father is to prevent the death of the suicidal baby by relocating hazardous objects out of the baby's reach, who in turn attempts to avoid the father's supervision, locking themselves inside heated ovens, swallowing batteries or shards of glass, and so on. The roughness of the visual presentation contributes to the funniness. The exaggerated character archetypes with silly-looking models and awkward animations - in addition to the ludicrousness of the unfolding catastrophe - make it clear that the game is not to be taken seriously. The game is hilarious because there is some truth in the setup. Vincent [30] describes the emotional core of the comedy: "Babysitting is a hard job because babies are irresponsible. They'll drink whatever's under the sink and stick forks in power outlets. It's not that they don't want to live, they just don't understand how life works."

\subsection{Global conflict}

Global conflict refers to the dispute between characters and the world they inhabit. Vorhaus [31] divides the global conflict into two scenarios: (1) where a normal character is part of a comical world, and (2) where a comical character is situated in a normal world. As video game worlds are all more or less fictional, the latter scenario, where the world is normal, is rare to come across.

Katamari Damacy ${ }^{16}$ is a portrayal of an interactive absurdist world. The storyline concerns a celestial little prince reconstructing the cosmos after his father, the flamboyant King of All Cosmos, had accidentally destroyed it while playing tennis. The re-assembling of the stars and the planets happens as the player rolls

\footnotetext{
${ }^{14}$ House House (Tentative release date 2018), Platforms no yet specified.

${ }^{15}$ Evil Tortilla Games (2015), Windows.

16 Namco (2004), Playstation 2.
} 
around a spherical object, called Katamari, that sticks any colliding objects to its surface. The rebuilding starts from a miniature scale, where the player is able to attach only small items, such as coins and butterflies, to the Katamari. As they keep on rolling, the snowballing sphere allows increasingly larger objects, such as stadiums and islands, or even rainbows, to stick to Katamari's surface.

Frog Fractions ${ }^{17}$ challenges game design conventions by making its gameplay sequences illogical. Frog Fractions presents itself as a simple edutainment browser game that wishes to educate the player about mathematical fractions. The player controls a frog on a lily pad trying to catch insects with its tongue. The score is displayed in fractions, but the lesson about them remains unclear. The nature of the game changes drastically as the player gains access to power-ups. Upon obtaining a dragon power-up with the ability to warp-drive, the player starts flying through outer space, landing on Mars - now colonized by bugs - and navigating its underwater caves while listening to a narration about the history of boxing. Frog Fractions is a collection of different gameplay styles. The style fluctuates from a space shoot 'em up, to a courtroom simulator, to a text adventure, to a rhythm action game. It is unabridged absurdity in video game format - a circus that subverts the audience's expectations to the most fundamental degree.

\section{Discussion and Conclusions}

The settings in video games contextualize and justify the players' actions in them. Video game worlds are hypernormalized realms, or as Huizinga [17] and later Salen and Zimmerman [27] define it, artificial spaces that suspend and replace the reality of the world and what is considered normal in it. Every video game wishes its audience to accept the implausibility that these worlds hold, hoping that the players would not question their artificial rules and boundaries. Video games aim to fascinate the players, because due to their freedom of movement, narrative details may hinge upon the players noticing them. Comedy can be regarded as a powerful way of captivating the players' attention, as it is an exceptionally charismatic way of conveying ludonarrative information to the players.

In order for ludonarrative comedy to work as intended, it requires to be highlighted. In this paper we have demonstrated, using examples of existing video games, various means of achieving this goal. These range from: (1) adopting a particular visual style, to (2) choosing a primary source of embedded, emergent, or even unintentional comedy, to (3) creating one or more types of inner, local, or global conflicts.

Further to these primary means of creating ludonarrative comedy, video games can also provide various humor enhancers, not only to captivate the players' curiosity, but also to prepare them for the full experience of humor [22]. Through these enhancers, game designers can highlight the comic premise of a game, and indirectly address the current state of affairs of the game world to

\footnotetext{
$\overline{17}$ Twinbeard Studios (2012), Browser game.
} 
the player. Despite their importance, we have not included a discussion of these types of comic enhancers here, due to the space limitations of this paper.

In summary, ludonarrative comedy seems to offer a lot of potential, but its inclusion creates unique challenges for game designers. Some of the main issues to consider in designing ludonarrative comedy are: (a) narratives are less linear compared to cinema and literature, (b) the element of gameplay should not only be taken into account, but utilized as the basis for every comedic part, (c) the pace is not controlled by the story architects, but by the player, and (d) the role of the game designer is often to just nudge the players in the right direction.

\section{References}

1. Abbott, M.: Knock em dead (2010), http://www.brainygamer.com/the_brainy_ gamer/2010/07/comedy.html, [Accessed in July 2018]

2. Barrett, R.: Chuck Jones' rules for writing road runner cartoons (2015), http://mentalfloss.com/article/62035/ chuck-jones-rules-writing-road-runner-cartoons, [Accessed in July 2018]

3. Bell, N.D.: Responses to failed humor. Journal of Pragmatics 41(9), 1825-1836 (2009), https://doi.org/10.1016/j.pragma.2008.10.010

4. Bogost, I.: Video games are better without stories (2017), https: //www.theatlantic.com/technology/archive/2017/04/video-games-stories/ 524148/, [Accessed in July 2018]

5. Cook, D.: Opinion: A theory about humor in games (2012), http: //www.gamasutra.com/view/news/39433/Opinion_A_Theory_About_Humor_ In_Games.php, [Accessed in July 2018]

6. Dille, F., Platten, J.Z.: The ultimate guide to video game writing and design. [Los Angeles] : Lone Eagle (2007)

7. Dormann, C.: Fools, tricksters and jokers: Categorization of humor in gameplay. In: Reidsma, D., Choi, I., Bargar, R. (eds.) Intelligent Technologies for Interactive Entertainment, pp. 81-90. Springer International Publishing (2014)

8. Dormann, C., Biddle, R.: A review of humor for computer games: Play, laugh and more. Simulation \& Gaming 40(6), 802-824 (2009), https://doi.org/10.1177/ 1046878109341390

9. Frasca, G.: Ludology meet narratology: Similitude and differences between (video)games and narrative (1999), http://www.ludology.org/articles/ ludology.htm, [Accessed in July 2018]

10. Furniss, M.: Chuck Jones: Conversations (Conversations with Comic Artists Series). University Press of Mississippi (2005)

11. Gonzalez, L.: A brief history of video game humor (2004), https://www .gamespot. com/articles/a-brief-history-of-video-game-humor/1100-6114407/, [Accessed in July 2018]

12. Gordon, M.: What makes humor aesthetic? International Journal of Humanities and Social Science 2(1), 62-70 (2012), http://www . ijhssnet.com/journals/Vol_ 2_No_1_January_2012/6.pdf

13. Grayson, N.: The $a^{* *}$ hole goose game is fun to play (2017), https://kotaku.com/ the-asshole-goose-game-is-fun-to-play-1820622256, [Accessed in July 2018]

14. Grönroos, A.M.: Humour in Video Games: Play, Comedy, and Mischief. Master's thesis, Aalto University (2013) 
15. Hocking, C.: Ludonarrative dissonance in bioshock (2007), http://clicknothing. typepad.com/click_nothing/2007/10/ludonarrative-d.html, [Accessed in July $2018]$

16. Hookham, G., Meany, M.: The spectrum of states: Comedy, humour and engagement in games. In: Proceedings of the 11th Australasian Conference on Interactive Entertainment. CRPIT, vol. 167, pp. 25-34. ACS, Sydney, Australia (2015), http://crpit.com/confpapers/CRPITV167Hookham.pdf

17. Huizinga, J.: Homo ludens: A study of the play-element in culture. Beacon Press Boston, MA (1967)

18. Juul, J.: The game, the player, the world: Looking for a heart of gameness (2003), http://www. jesperjuul.net/text/gameplayerworld/, [Accessed in July 2018]

19. Knox, I.: Towards a philosophy of humor. The Journal of Philosophy 48(18), 541548 (1951), http://www.jstor.org/stable/2020793

20. Koestler, A.: The Act of Creation. Hutchinson \& co, London (1964)

21. Mackey, B.: No laughing matter: Making humor work in games (2009), http://www.gamasutra.com/view/feature/132586/no_laughing_matter_ making_humor_.php, [Accessed in July 2018]

22. Marszalek, A.: Humorous worlds: a cognitive stylistic approach to the creation of humour in comic narratives. Master's thesis, University of Glasgow (2012)

23. Martin, R.: The Psychology of Humor. Academic Press (2006)

24. Morreall, J.: Humor and aesthetic education. Journal of Aesthetic Education 15(1), 55-70 (1981), http://www.jstor.org/stable/3332209

25. Pratchett, R., Schafer, T., Teti, J., Vanaman, S.: Make 'Em Laugh: comedy in games (2010), http://www.gdcvault.com/play/1012287/ Make-Em-Laugh-Comedy-in, [Accessed in July 2018]

26. Quinn, Z.: Comedy games: An underexplored genre (2015), http://www.gdcvault. com/play/1021867/Comedy-Games-An-Underexplored, [Accessed in July 2018]

27. Salen, K., Zimmerman, E.: Rules of Play: Game Design Fundamentals. The MIT Press (2003)

28. Totilo, S.: Joystuck: Why aren't video games funny? (2004), http://www.slate. com/articles/technology/gaming/2004/11/joystuck.html, [Accessed in July 2018]

29. Vandaele, J.: Humor mechanisms in film comedy: Incongruity and superiority. Poetics Today 23(2), 221-249 (2002), https://doi.org/10.1215/ 03335372-23-2-221

30. Vincent, B.: Keep your infant son from death in 'who's your daddy' (2015), https://motherboard.vice.com/en_us/article/z43vew/ keep-your-infant-son-from-death-in-whos-your-daddy, [Accessed in July 2018]

31. Vorhaus, J.: The comic toolbox how to be funny even if you're not. Los Angeles Silman-James Press, 1st edn. (1994)

32. Švelch, J.: Comedy of contingency: Making physical humor in video game spaces. International Journal of Communication 8 (2014), http://ijoc.org/index.php/ ijoc/article/view/2687

33. Weinstock, J.A.: Taking South Park Seriously. State University of New York Press (2008)

34. Zhou, T.: Chuck Jones' rules for writing road runner cartoons (2016), https: //vimeo.com/133693532, [Accessed in July 2018] 